\title{
Caracterização anatômica, composição química e atividade citotóxica de Talinum triangulare (Jacq.) Willd (Portulacaceae)
}

\author{
Anatomical characterization, chemical composition and cytotoxic activity of Talinum \\ triangulare (Jacq.) Willd (Portulacaceae)
}

\section{Beatriz Gonçalves Brasileiro', Joseane Bessa Barbosa², Claudia Masrouh Jamal', Olívia Gonçalves Leão Coelho ${ }^{2}$, Rikeller Ronchi ${ }^{3}$ e Virgínia Ramos Pizziolo ${ }^{2}$}

\author{
${ }^{1}$ Instituto Federal de Ciência e Tecnologia do Sudeste - MG - Muriaé, MG, Brasil \\ beatriz.brasileiro@ifsudestemg.edu.br \\ 2 Universidade Federal de Viçosa, Viçosa, MG, Brasil \\ joseanebessa@gmail.com; oliviaglc@hotmail.com; virginia.pizziolo@ufv.br \\ ${ }^{3}$ Universidade Federal do Espírito Santo, Vitória, ES, Brasil \\ cmjamal@gmail.com; rikeller_ronchi@hotmai.com
}

\begin{abstract}
Resumo
O objetivo do trabalho foi estudar a anatomia, a composição química, e a atividade citotóxica do extrato de Talinum triangulare. Folhas e fragmentos de caules foram fixados, seccionados e corados seguindo técnicas usuais em anatomia. A triagem fitoquímica foi realizada de acordo com testes clássicos para detecção de metabólitos secundários. A citotoxicidade foi avaliada utilizando como modelo a letalidade de larvas de Artemia salina. A folha é anfiestomática e possui epiderme uniestratificada, recoberta por cutícula delgada. O mesofilo é dorsiventral e a nervura central é constituída por feixe vascular colateral. Na porção apical, o caule possui feixes colaterais delimitando a medula e a região cortical. Uma camada de colênquima angular é encontrada adjacente à epiderme. Na porção basal, o caule apresenta cerca de quatro camadas de colênquima angular e células parenquimáticas volumosas limitando internamente o córtex. A triagem fitoquímica detectou a presença de alcaloides, flavonoides, cumarinas, terpenos e esteroides. O principal nutriente encontrado foi o nitrogênio, seguido do potássio e do magnésio, sendo as folhas ricas em ferro. O extrato etanólico não se mostrou tóxico para larvas de $A$. salina, apresentando DL50 > 1000 ppm, o que comprova a segurança do uso dessa espécie na terapêutica popular.
\end{abstract}

Palavras-chave: Anatomia, composição mineral, morfologia, perfil fitoquímico.

\begin{abstract}
This study aimed to assess chemical compositions and anatomy of Talinum triangulare extract and its cytotoxic activity in order to improve the knowledge of the specie. Leaves and stem fragments were fixed, sectioned and stained following the usual techniques in anatomy. The phytochemical screening was performed according to classical tests for secondary metabolites detection. Cytotoxicity was evaluated using as model the lethality of Artemia salina larvae. The studied leaf is amphistomatic and presents uniseriate epidermis covered by thin cuticle. The mesophyll is dorsiventral and the midrib consists of collateral vascular bundle. In the apical portion, the stem has vascular bundles delimiting the medular and cortical regions. A stratum of angular collenchyma is found beneath the epidermis. In the basal portion, the stem has about four layers of angular collenchyma and voluminous parenchyma cells internally delimiting the cortex. The phytochemical screening detects the presence of alkaloids, flavonoids, coumarins, terpenes and steroids. The mineral composition showed that the major element found was nitrogen, followed by potassium and magnesium, and the leaves are iron rich. The ethanolic extract did not show toxicity in the larvae of A. salina, with LD50> 1000 ppm, which proves the safe use of this specie in popular therapy.
\end{abstract}




\section{Introdução}

Portulacaceae possui distribuição cosmopolita incluindo cerca de 30 gêneros e 400 espécies de distribuição predominantemente tropical e subtropical. No Brasil ocorrem apenas os gêneros Portulaca e Talinum e aproximadamente 30 espécies. Talinum inclui cerca de cinquenta espécies e está distribuído nos trópicos, subtrópicos e regiões temperadas do mundo (SOUZA \& LORENZI, 2005).

Talinum triangulare (Jacq.) Willd é provavelmente originária da América do Sul, entretanto, sua origem africana também é discutida devido às várias espécies ocorrentes no Continente Africano (LORENZI, 2000). A espécie é usada na alimentação, em países africanos, principalmente pelo seu valor nutricional e baixo custo (NYA et al., 2010; FASUYI, 2007). No Brasil, as folhas são utilizadas como hortaliça (CARIBE \& CAMPOS, 1991), principalmente nas regiões norte e nordeste (BRASIL, 2002). Na medicina tradicional, toda a planta é usada para tratar várias doenças, incluindo doenças hepáticas (LIANG et al., 2011 ), sarampo e diabetes (FONTEM \& SCHIPPERS, 2004), distúrbios diuréticos e gastrointestinais (MENSAH et al., 2008), cicatrização (MORS et al., 2000; AGRA et al., 2008) e como imunoestimulante (AGBONON et al., 2009). Ainda, o extrato aquoso de T. triangulare possui destacada atividade antioxidante (ANDARWULAN et al., 2010).

A Agência Nacional de Vigilância Sanitária (ANVISA), por meio da Resolução RDC 10, de 14/abril/2010, estabeleceu que a solicitação do registro de fitoterápicos só ocorre mediante, entre outros documentos, a identificação botânica oficial da planta que compõe a matéria prima de origem, bem como do laudo de identificação macro e microscópico do órgão vegetal utilizado, emitido por profissional habilitado (BRASIL, 2010). Desta forma, a anatomia vegetal pode subsidiar o controle de qualidade de fármacos de origem vegetal, de grande valia quando as plantas são comercializadas e/ou utilizadas in natura (DUARTE \& MENARIM, 2006; LEITE et al., 2007), constituindo instrumento eficaz na detecção de fraudes ou uso de plantas erroneamente identificadas (TOLEDO et al.,
2006; BUDEL \& DUARTE, 2008; EMPINOTTI \& DUARTE, 2008; GOMES et al., 2009).

Plantas que eventualmente possam despertar interesse na exploração de alimentos e de compostos com propriedades terapêuticas, como é o caso de T. triangulare, carecem de pesquisas e estudos com fins de preservação, cultivo e validação farmacognóstica. Desta forma, o objetivo deste trabalho foi descrever a anatomia e a constituição química das partes vegetativas aéreas, bem como verificar a atividade citotóxica do extrato de T. triangulare, fornecendo subsídios a padronização e ao controle de qualidade do produto.

\section{Material e Métodos}

O material vegetal foi obtido de plantas propagadas por meio de sementes e cultivadas em casa de vegetação do Departamento de Fitotecnia da UFV, em Viçosa, MG.

A caracterização anatômica foi realizada em folhas adultas, coletadas na região do $5^{\circ}$ nó a partir do ápice caulinar, sendo a amostragem realizada no terço médio da lâmina foliar. Os segmentos caulinares foram retirados nas regiões apical e basal da planta. As amostras foram fixadas em $\mathrm{FAA}_{50}$ por 48 horas e estocadas em etanol 70\% (JOHANSEN, 1940). As amostras foram desidratadas em série etanólica crescente e incluídas em metacrilato (Leica Historesin ${ }^{\circledR}$ ). Secções com $5 \mu \mathrm{m}$ de espessura foram obtidas em micrótomo rotativo de avanço automático, coradas com azul de toluidina (O'BRIEN et al., 1964) e montadas com lamínula e resina sintética (Permount $(\AA)$. Cortes paradérmicos foram obtidos em folhas frescas, na região mediana do limbo foliar, corados com violeta cristal aquoso e montados em gelatina glicerinada (KRAUS; ARDUIN, 1997).

A análise da composição mineral foi realizada em folhas adultas, secadas em estufa a $50^{\circ} \mathrm{C}$ e moídas em moinho de facas. Foram determinadas as concentrações: de fósforo (P), pelo método da vitamina $\mathrm{C}$ modificado (BRAGA \& DE FELLIPO, 1974); de potássio (K), por fotometria de chama (SARRUGE \& HAAG, 1974); de enxofre (S), por turbidimetria do sulfato (JACKSON, 1958); e de cálcio (Ca), magnésio $(\mathrm{Mg})$, ferro $(\mathrm{Fe})$, zinco $(\mathrm{Zn})$, manganês $(\mathrm{Mn})$ e cobre $(\mathrm{Cu})$, por espectrofotometria de absorção atômica (AOAC, 1975). A determinação 
da concentração de nitrogênio total $(\mathrm{N})$ pelo método Kjeldahl, foi feita após a digestão sulfúrica das amostras (SANTOS, 2007).

$\mathrm{Na}$ realização da triagem fitoquímica, caules e folhas foram colhidos, secados, pulverizados e extraídos por maceração utilizando etanol como solvente. Após eliminação do solvente sob vácuo e temperatura inferior a $40^{\circ} \mathrm{C}$, os extratos brutos obtidos foram submetidos a testes clássicos (WAGNER et al., 1984) para detectar as classes de metabólitos secundários presentes.

O efeito citotóxico foi avaliado utilizando a toxicidade em larvas de Artemia salina Leach. (MEYER et al., 1982). Dez larvas de A. salina em estado nauplii (48 horas após a eclosão) foram expostas a diluições dos extratos brutos, preparadas como descrito a seguir. Os extratos foram solubilizados em $0,2 \mathrm{~mL}$ de dimetilsulfóxido (DMSO) e o volume foi completado para $20 \mathrm{~mL}$ com solução salina (36 $\mathrm{g} / \mathrm{L})$, fornecendo uma diluição de 1000 ppm. Desta solução foram preparadas diluições sucessivas (500, 250 e 125 ppm). Como controle positivo foi utilizado dicromato de potássio (2 mg) solubilizado em $0,2 \mathrm{~mL}$ de DMSO e acrescentado de quantidade suficiente de solução salina para completar $20 \mathrm{~mL}$. Tubos contendo 0,2 mL de DMSO e 10 larvas de $A$. salina, nas mesmas condições da amostra foram utilizados como controle negativo. Os tubos foram mantidos sob luz e, após de 24 horas, as larvas sobreviventes foram contadas. O cálculo da DL50 foi realizado utilizando o programa PROBITOS (MEYER et al., 1982).

\section{Resultados e Discussão}

\subsection{Caracterização anatômica da folha}

A folha de T. triangulare é glabra e possui epiderme uniestratificada composta por células com paredes anticlinais sinuosas nas faces adaxial (Figura 1A) e abaxial (Figura 1B), revestidas de cutícula delgada. Estômatos ocorrem nas duas faces da folha, inseridos no mesmo nível das demais células epidérmicas, caracterizando a folha como anfiestomática. Portulacaceae se caracteriza por possuir estômatos paracíticos, anomocíticos ou diacíticos (CRONQUIST, 1981) sendo que em T. triangulare predomina o tipo anomocítico na epiderme adaxial e o paracítico na epiderme abaxial (Figuras 1A, B), com a presença de câmara subestomática, como pode ser observado na Figura 1C. As características da epiderme de $T$. triangulare estão em correspondência com o padrão encontrado em Portulaca oleraceae, outra espécie de Portulacaceae (KUMAR et al., 2008). Segundo Mott et al. (1982), a característica anfiestomática pode representar o meio de aumentar a taxa fotossintética, por permitir a troca gasosa eficiente, se comparada com outros tipos de folhas.

O mesofilo é dorsiventral, sendo constituído por cerca de três camadas de parênquima paliçádico atípico, cujas células são largas, comparativamente curtas e pouco diferenciadas do parênquima lacunoso. $\mathrm{O}$ parênquima lacunoso é composto por células hipertrofiadas, semelhantes ao parênquima aquífero, e idioblastos contendo drusas de oxalato de cálcio (Figura 1C), conforme o padrão de Portulacaceae (Cronquist, 1981). Cristais de oxalato de cálcio são encontrados no interior de idioblastos e podem apresentar diferentes funções, como armazenagem de cálcio, na manutenção do equilíbrio iônico, na detoxificação e na proteção contra o ataque de herbívoros (NAKATA, 2003). Cristais semelhantes aos observados nesta análise são descritos em representantes da família (METCALFE; CHALK, 1957). Na região mediana do mesofilo, feixes vasculares colaterais de pequeno porte são envoltos por células parenquimáticas (Figura 1C).

Em secção transversal, a nervura central mostra formato côncavo-convexo sendo percorrida por um feixe vascular colateral envolto por células parenquimáticas volumosas com poucos cloroplastos, sem tecidos de sustentação (Figuras 1D-E). O pecíolo é curto e possui, em secção transversal, formato triangular, com disposição de tecidos semelhante à nervura central. Foi identificada uma bainha de células volumosas envolvendo o feixe vascular (Figura 1G), semelhante à verificada em Portulaca oleraceae (KUMAR et al., 2008). 

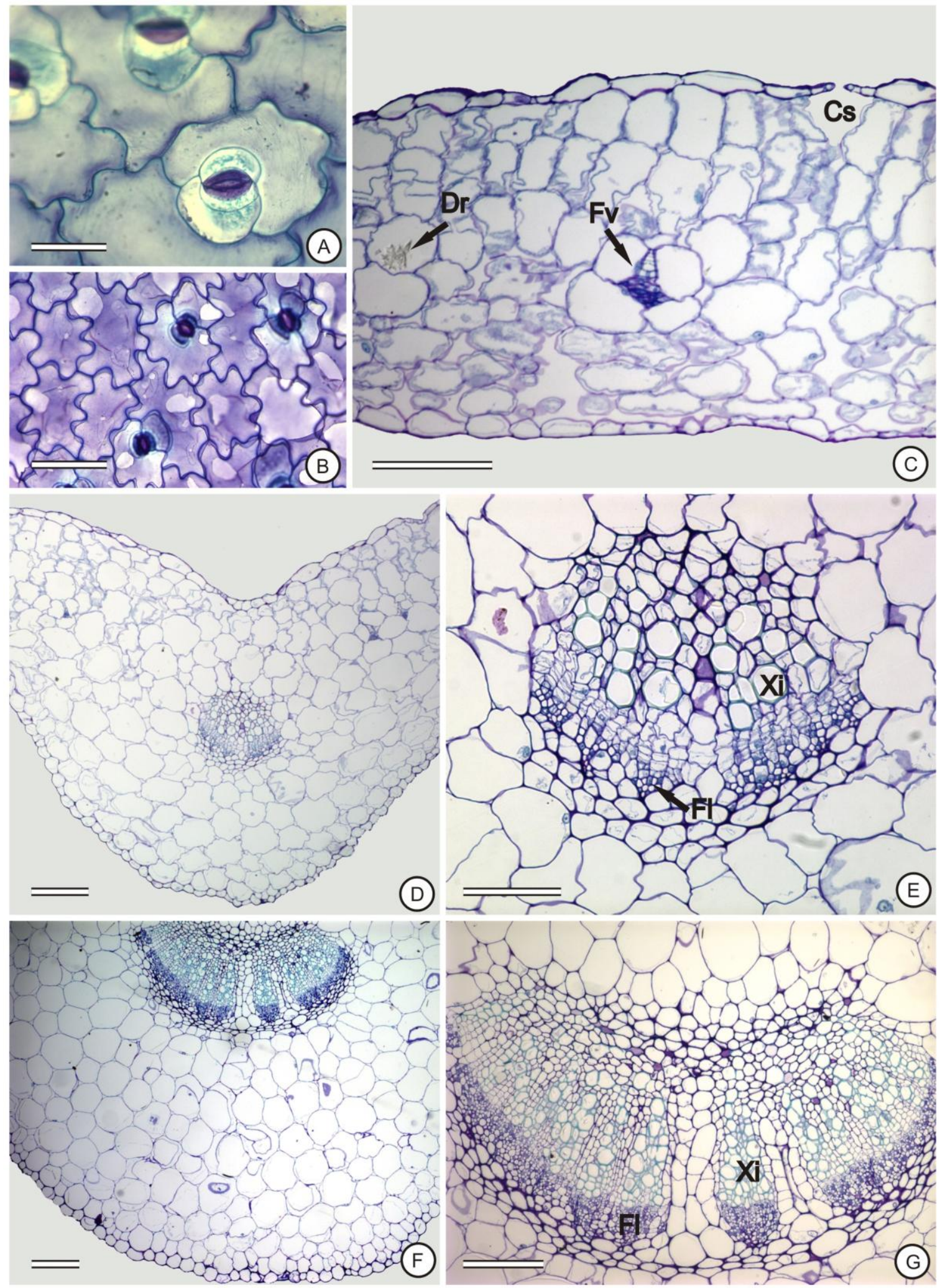

Figura 1 - Fotomicrografias de secções paradérmicas (A, B) e transversais (C-G) do limbo foliar de T. triangulare. A, epiderme, face adaxial. B, epiderme, face abaxial. C, aspecto geral da região intervenal. $\mathbf{D}$, aspecto geral da nervura central. E, feixe vascular da nervura central. $\mathbf{F}$, aspecto geral do pecíolo. G, feixe vascular do pecíolo. Dr, drusas; Cs, câmara subestomática; Fv, feixe vascular;

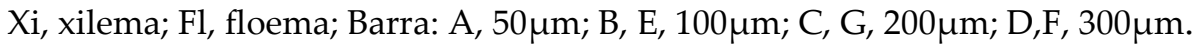




\subsection{Caracterização anatômica do caule}

O ápice caulinar em secção transversal é triangular e possui estrutura eustélica (Fig. 2A), com feixes colaterais delimitando a medula e a região cortical (Fig. 2B), composta por células parenquimáticas volumosas (Fig. 2C). A epiderme é constituída por uma camada de células com paredes finas e poucos estômatos e a porção subepidérmica é caracterizada por uma camada de células de colênquima angular (Figura 2D).

$\mathrm{Na}$ porção basal, o caule apresenta formato circular, em secção transversal. A epiderme é uniestratificada, com células alongadas no sentido periclinal e revestidas por cutícula delgada. Abaixo da epiderme são observadas cerca de quatro camadas de colênquima angular (Figura 2E) e células parenquimáticas volumosas limitando internamente o córtex (Figura 2F), conforme verificado em Portulaca oleracea, espécie também pertencente à família Portulacaceae (KUMAR et al., 2008). Pequenas calotas de fibras perivasculares são encontradas na região próxima ao floema (Figura 2G). Cristais de oxalato de cálcio são encontrados no parênquima medular e ocasionalmente vistos na região cortical (Figura 2H). Drusas também são relatadas em Portulaca oleracea (KUMAR et al., 2008). O sistema vascular apresenta crescimento secundário incipiente, com a presença de câmbio fascicular e interfascicular, porém, sem a formação de tecidos secundários na região interfascicular (Figuras 2E e 2G). O parênquima medular compõe-se de células parenquimáticas volumosas, de paredes delgadas, parcialmente colapsadas (Figura 2F ).

\subsection{Triagem fitoquímica}

Os testes da triagem fitoquímica permitiram a identificação dos tipos de substâncias presentes nos extratos, conforme Tabela 1. Esses resultados contribuem para a definição de parâmetros de controle da qualidade para utilização dos extratos de T. triangulare.
Tabela 1 - Resultado dos testes fitoquímicos indicadores da presença das principais classes de substâncias em T. triangulare (Jacq.) Willd

(Portulacaceaae)

\begin{tabular}{c|c|c}
\hline Substância & Folha & Caule \\
\hline Alcaloides & + & + \\
Flavonoides & + & + \\
Saponinas & - & - \\
Triterpenos & + & - \\
Esteroides & - & + \\
Taninos & - & - \\
Cumarinas & + & + \\
Heterosídeos antracênicos & - & - \\
Naftoquinonas & - & - \\
\hline
\end{tabular}

\subsection{Composição mineral}

A composição mineral das folhas de $T$. triangulare encontra-se na Tabela 2, sendo que o principal nutriente encontrado foi o nitrogênio (N) com concentração de $3663 \mathrm{mg} / 100 \mathrm{~g}$, seguido do potássio (K) (3546 mg/100g) e do magnésio $(\mathrm{Mg}) \quad(1983 \mathrm{mg} / 100 \mathrm{~g})$. Estudo realizado por outros autores também mostrou que o caule e folhas de T. triangulare são ricos em compostos nitrogenados e que estes são certamente responsáveis pelas propriedades biológicas desta planta (AMORIM et al., 2014). Também foi verificado que as folhas de $T$. triangulare são ricas em ferro, cujo conteúdo encontrado foi 14,33 $\mathrm{mg} / 100 \mathrm{~g}$ de biomassa seca.

Pelos resultados das determinações de minerais a ingestão de $100 \mathrm{~g}$ de $T$. triangulare atende as necessidades diárias de ferro $(\mathrm{Fe})$, zinco $(\mathrm{Zn})$, manganês $(\mathrm{Mn})$ e magnésio $(\mathrm{Mg})$ segundo a Ingestão Diária Recomendada (IDR) aos adultos, de acordo com a RDC 269 (BRASIL, 2005) (Tabela 2). No entanto, deve ser considerada a biodisponibilidade destes nutrientes, ou seja, a fração do mineral que é aproveitada pelo organismo por meio da absorção em relação ao teor total consumido. Essa absorção está relacionada com a forma química que estes elementos se encontram nos alimentos (FRANCO, 2007). A biodisponibilidade de um elemento pode ser afetada negativamente pela presença de fitatos, compostos fenólicos, fibras e alguns minerais entre outros (QUEIROZ \& TORRES, 1995). 

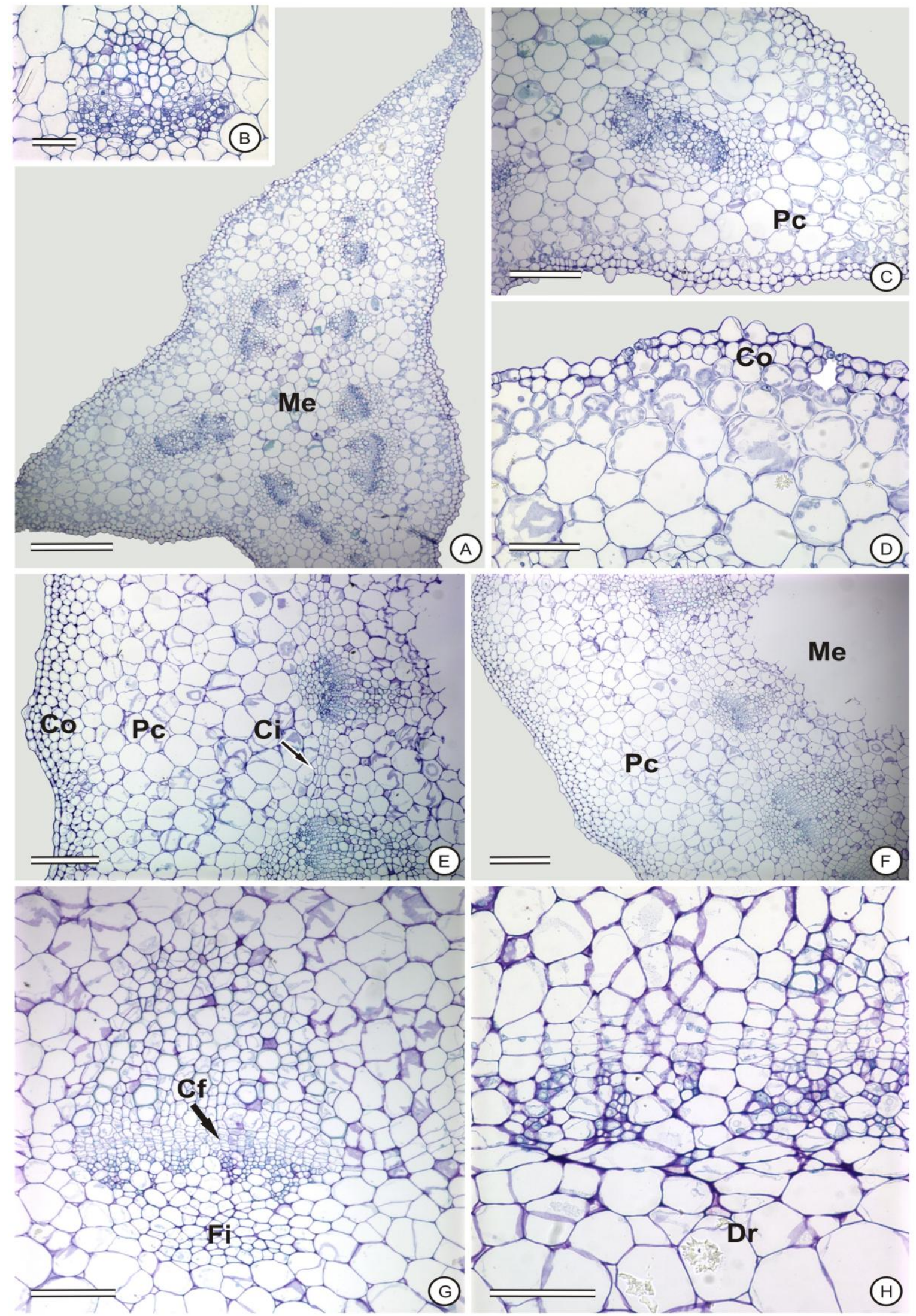

Figura 2 - Fotomicrografias de seções transversais do caule de T. triangulare. A-D, região apical do caule. E-H, região basal do caule. Me, medula; $\mathrm{Pc}$, parênquima cortical; $\mathrm{Co}$, colênquima; $\mathrm{Ci}$, cambio interfascicular; Cf, cambio fascicular; Fi, fibras; Dr, drusa; Barra: A, $500 \mu \mathrm{m} ; \mathrm{B}, 50 \mu \mathrm{m} ; \mathrm{C}, 200 \mu \mathrm{m}$; D, $100 \mu \mathrm{m} ; \mathrm{E}, 300 \mu \mathrm{m}$. F, $400 \mu \mathrm{m} ; \mathrm{G}, \mathrm{H}, 150 \mu \mathrm{m}$ 
Segundo Aletor e Adeogum (1995), o alto conteúdo de fibras e a presença de alguns fatores antinutricionais, como por exemplo, oxalato e ácido fítico, podem afetar o valor nutricional de T. triangulare. $\mathrm{O}$ ácido fítico pode ligar-se com proteínas e formar um complexo que afeta a digestibilidade proteica por meio da inibição de enzimas digestivas do trato gastrointestinal (REDDY et al., 1982). Entretanto, a secagem das folhas (FASUYI, 2006) e o aquecimento (SEENA et al., 2006) parece reduzir e/ou eliminar alguns destes fatores, como o acido fítico e taninos, melhorando o valor nutricional do alimento.

A composição mineral de $T$. triangulare é comparável e, em alguns casos, maior que outros vegetais de uso convencional na alimentação humana, já que apresenta superioridade em relação ao conteúdo de boro (Bo), cobre $(\mathrm{Cu})$ e magnésio $(\mathrm{Mg})$, quando comparada a outras folhosas de uso convencional como agrião, couve e espinafre (BRASIL, 2011). O conteúdo de ferro também chama atenção, por ser maior que o conteúdo encontrado em folhas de espinafre, repolho e salsa, vegetais considerados ricos neste nutriente (FURLANI et al., 1978). Pesquisas desenvolvidas no continente africano também mostraram que T. triangulare possui altos níveis de cálcio $(\mathrm{Ca})$, sódio $(\mathrm{Na})$, potássio $(\mathrm{K})$, magnésio $(\mathrm{Mg})$ e fósforo (P) (FASUYI, 2007). O conteúdo de zinco (Zn) obtido nas folhas confere com os dados de Aremu e Udoessien (1990), que também verificaram alto teor de $\mathrm{Zn}$ em plantas de $T$. triangulare obtidas em mercados da Nigéria.
Esses dados tornam-se importantes quando se relaciona a alta prevalência de deficiências de minerais e suas consequências à saúde. Como exemplo, pode ser citado a deficiência de ferro que é um dos grandes problemas de saúde pública em todo o planeta (GAY et al., 2009) e considerado responsável pela maior parte das anemias encontradas (QUEIROZ \& TORRES, 2000).

Deve-se atentar também à concentração de manganês, pois de acordo com os dados obtidos, o consumo diário de $100 \mathrm{~g}$ de $T$. triangulare já ultrapassa a necessidade diária de pessoas adultas. A riqueza desse mineral deve ser nutricionalmente considerada, embora seja absorvido no intestino delgado da mesma forma que o ferro, e compete com esse mineral pelo mesmo sítio de absorção (FINLEY, 1999), dificultando o seu aproveitamento pelo organismo. Outro fato relevante sobre a ingestão excessiva de manganês é o seu possível acúmulo no fígado e no sistema nervoso central, produzindo sintomas semelhantes aos da doença de Parkinson (FINLEY, 1994), por isso, o consumo deve ser moderado até que estudos toxicológicos estabeleçam limite de ingestão tolerável.

De acordo com Fasuyi (2007), T. triangulare tem potencial alimentar principalmente como fonte de proteína e minerais, já que, além dos minerais, também apresenta alto teor de proteína (19\%) e vitaminas, revelando grande valor nutricional (AREMU \& UDOESSIEN, 1990; FASUYI, 2006; TCHIÉGANG \& AISSATOU, 2004).

Tabela 2 - Teores de nutrientes presentes nas folhas de Talinum triangulare (Jacq.) Willd e Ingestão Diária Recomendada (IDR)

\begin{tabular}{|c|c|c|c|c|c|}
\hline \multicolumn{2}{|c|}{$\begin{array}{c}\text { Nutrientes } \\
(\mathrm{mg} / 100 \mathrm{~g} \text { de amostra seca })\end{array}$} & \multirow[t]{2}{*}{$\mathrm{IDR}^{*}$} & $(\mathrm{mg} / 100 \mathrm{~g}$ & stra seca) & $\mathrm{IDR}^{*}$ \\
\hline Nitrogênio & 3663 & & Zinco & 4,24 & 7 \\
\hline Fósforo & 436 & 700 & Ferro & 14,33 & 14 \\
\hline Potássio & 3546 & & Manganês & 4,69 & 2,3 \\
\hline Sódio & 31 & & Cobre & 1,79 & 0,9 \\
\hline Cálcio & 678 & 1000 & Boro & 2,34 & \\
\hline Magnésio & 1983 & 260 & & & \\
\hline Enxofre & 321 & & & & \\
\hline
\end{tabular}

*Brasil, 2005. 
Vegetais considerados de uso tradicional, como é o caso de $T$. triangulare, atualmente são menos utilizados em favor de outras espécies exóticas. Por outro lado, a disponibilidade destes vegetais tem declinado drasticamente devido ao aumento de outras culturas que incluem eliminação química de vegetais selvagens e mudança no habitat. Este fato tem ocorrido em várias comunidades rurais, em vários países do continente Africano, como relata Odhav et al. (2007). Segundo Nesamvuni et al. (2001), pessoas jovens ignoram as plantas nutricionalmente ricas, resultando em dietas pobres e aumento da incidência de deficiência nutricional e doenças em muitas partes da África.

O extrato etanólico de T. triangulare não apresentou atividade citotóxica frente Artemia salina, apresentando DL50 > 1000ppm, o que comprova a segurança de utilização destas espécies.

\section{CONCLUSÕES}

O extrato etanólico testado não apresentou atividade citotóxica, o que pode sugerir segurança do uso dessa espécie na terapêutica popular. Os resultados da triagem fitoquímica contribuem com a determinação de parâmetros de avaliação de qualidade de $T$. triangulare, face ao seu uso medicinal e mostram seu potencial como alternativa alimentar, terapêutica ou como suplemento nutricional. Adicionalmente, os dados obtidos neste trabalho podem orientar agricultores e as indústrias de alimentos no desenvolvimento de novos produtos e apoiar políticas de proteção ao meio ambiente e da biodiversidade.

\section{REFERÊNCIAS}

AGBONON, A.; EKLU-GADEGBEKU, K.; AKLIKOKOU, K.; GBEASSOR,M.; KOFFI AKPAGANA, TERESA W. TAM, JOHN THOR ARNASON, BRIAN C. FOSTER. In vitro inhibitory effect of West African medicinal and food plants on human cytochrome P450 3A subfamily. Journal of Ethnopharmacology, v.128, p.390-394, 2009.
AGRA, M.F.; SILVA, K.N.; BASÍLIO, I.J.L.D.; FRANÇA, P.F.; BARBOSA-FILHO, J.M. Survey of medicinal plants used in the region Northeast of Brazil. Revista Brasileira de Farmacognosia, v.18, p.472-508, 2008.

ALETOR, V.A.; ADEOGUN, O.A. Nutrients and antinutrient components of some tropical leafy vegetables. Food Chemistry, v.54, p.375-379, 1995.

AMORIM, A.P.O.; CARVALHO JUNIOR, A.R.; LOPES, N.P.; CASTRO, R.N.; OLIVEIRA, M.C.C.; CARVALHO, M.G. Chemical compounds isolated from Talinum triangulare (Portulacaceae). Food Chemistry, v. 160, p. 204-208, 2014.

ANDARWULAN, N.; BATARI, R.; SANDRASARI, D. A.; BOLLING, B.; WIJAYA, H. Flavonoid content and antioxidant activity of vegetables from Indonesia. Food Chemistry, v.121, n.4, p.1231-1235, 2010 .

AOAC Association of official analytical chemists 1975. Official methods of analysis. Washington, D.C.

AREMU, C.Y.; UDOESSIEN, E.I. Chemical estimation of some inorganic elements in selected tropical fruits and vegetables. Food Chemistry, v. 37, p. 229-234, 1990.

BRAGA, J.M.; DE FELLIPO, B.V. Determinação espectofotométrica de fósforo em extratos de solos e plantas. Revista Ceres, v. 21, p. 73-85, 1974.

BRASIL. Ministério da Saúde. Agência Nacional de Vigilância Sanitária. Resolução de Diretoria Colegiada no. 269 de 22 de setembro de 2005. Aprova o regulamento técnico sobre a ingestão diária recomendada (IDR) de proteína, vitaminas e minerais, junto ao Sistema Nacional de Vigilância Sanitária. DOU. Diário Oficial da União, Poder Executivo, DF, Brasília, 23 set. 2005.

BRASIL. Ministério da Saúde. Agência Nacional de Vigilância Sanitária. Resolução de Diretoria Colegiada no. 14 de 31 de março de 2010. Dispõe sobre o registro de medicamentos fitoterápico. DOU. Diário Oficial da União, Poder Executivo, DF, Brasília, 05 abril 2010.

BRASIL. Ministério da Saúde. Secretaria de Políticas de Saúde. Coordenação-Geral da Política de Alimentação e Nutrição. Alimentos regionais brasileiros. Brasília: Ministério da Saúde. (Série F. Comunicação e Educação em Saúde; n. 21). 2002.

BRASIL. Ministério da Saúde. Tabela Brasileira de Composição de Alimentos. 4 ed. Campinas, 2011.

BUDEL, J.M.; DUARTE, M.R. Estudo farmacobotânico de partes vegetativas aéreas de Baccharis anomala DC., Asteraceae. Revista Brasileira de Farmacognosia, v. 18, p. 761-768, 2008. 
CARIBÉ, J.; CAMPOS, J.M. Plantas que ajudam o homem. São Paulo: Cultrix/Pensamento. 1991.

CRONQUIST, A. An integrated system of classification of flowering plants. New York: Columbia University. 1981.

DUARTE, M.R.; MENARIM, D.O. Morfodiagnose da anatomia foliar e caulinar de Camellia sinensis (L.) Kuntze, Theaceae. Revista Brasileira de Farmacognosia, v. 16, p.545-551, 2006.

EMPINOTTI, C.B.; DUARTE, M.R. Estudo anatômico de folha e caule de Elephantopus mollis Kunth (Asteraceae). Revista Brasileira de Farmacognosia, v. 18, p. 108-116, 2008.

ESPÍRITO SANTO, E.; PUGIALLI, H.R.L. Estudo da plasticidade anatômica foliar de Stromanthe thalia (Vell.) J.M.A. Braga (Marantaceae) em dois ambientes de Mata Atlântica. Rodriguésia, v. 50, p. 107-122, 1998.

FASUYI, A.O. Bio-nutritional evaluations of three tropical leaf vegetables (Telfairia occidentalis, Amaranthus cruentus and Talinum triangulare) as sole dietary protein sources in rat assay. Food Chemistry, v. 103, p. 757-765, 2007.

FASUYI, A.O. Nutritional potentials of some tropical vegetable leaf meals: chemical characterization and functional properties. African Journal of Biotechnology, v. 5, p. 49-53, 2006.

FINLEY, J.W. Sex affects manganese absorption and retenhon by humans from a diet adequate in manganese. The American Journal of Clinical Nutrition, v. 60, p.949-955, 1994.

FINLEY, J.W. Manganese absorption and retention by young women is associated with serum ferritin concentration. The American Journal of Clinical Nutrition, v. 70, p.37-43, 1999.

FONTEM, D.A.; SCHIPPERS, R.R. Talinum triangulare (Jacq.) Willd. Record from Protabase. Grubben, G.J.H. \& Denton, O.A. (Editors). PROTA (Plant Resources of Tropical Africa / Ressources vegetales de l'Afrique tropicale), Wageningen, Netherlands. 2004. http://database.prota.org/search.htm, acesso em março 2007.

FRANCO, G. Tabela de Composição de Alimentos. São Paulo: Atheneu. 2007.

FURLANI, A.M.C.; FUKLANI, P.R.; BATAGLIA, O.C.; HIKOCE, R.; GALLO, J.R. Composição mineral de diversas hortaliças. Bragantia, v. 37, p. 33-44, 1978.

GAY, E.A.S. FERGUSON, E.L.; HEATH, A.L.M.; GRAY, A.R.; GIBSON, R.S. Food-based strategies improve iron status in toddlers: a randomized controlled trial. American Journal of Clinical Nutrition, v.90, p.1541-1551, 2009.
GOMES, R.S.D.L.; OLIVEIRA, V.C.; JÁCOME, R.L.R.P.; PINTO, J.E.B.P.; LAMEIRA, O.A.; BARROS, A.M.D. Estudo morfoanatômico comparativo entre a poaia (Psychotria ipecacuanha (Brot.) Stokes - Rubiaceae) obtida da região Amazônica (habitat original) e proveniente de processo biotecnológico submetida a diferentes tratamentos de interceptação da radiação solar. Revista Brasileira de Farmacognosia, v. 19, p. 276283, 2009.

JACKSON, M.L. Soil chemical analysis. New Jersey: Prentice Hall, Inc. 1958.

JOHANSEN, D.A. Plant microtechnique. New York: McGraw-Hill Book Co. Inc.1940.

KRAUS, J.E.; ARDUIN, M. Manual básico de métodos em morfologia vegetal. Rio de Janeiro: EDUR. 1997.

KUMAR, B.S.A.; PRABHAKARN, V.; LAKSHMAN, K.; NANDEESH, R.; SUBRAMANYAM, P.; KHAN, S.; RANGANAYAKALU, D.; KRISHNA, N.V. Pharmacognostical studies of Portulaca oleracea Linn. Revista Brasileira de Farmacognosia, v. 18, p. 527-531, 2008.

LEITE, J.P.V.; PIMENTA, D.S.; GOMES, R.S.D. L.; DANTAS-BARROS, A. M. Contribuição ao estudo farmacobotânico da Echinodorus macrophyllus (Kunth) Micheli (chapéu-de-couro) - Alismataceae. Revista Brasileira de Farmacognosia, v. 17, p. 242248, 2007.

LIANG, D.; ZHOU, Q.; GONG, W.; WANG, Y.; NIE, Z.; HE, H.; LI, J.; WU, J.; WU, C.; ZHANG, J. Studies on the antioxidant and hepatoprotective activities of polysaccharides from Talinum triangulare. Journal of Ethnopharmacology, v.136, p.316-321, 2011.

LORENZI H. Plantas Daninhas do Brasil. Nova Odessa, SP: Instituto Plantarum. 2000.

LORENZI, H.; MATOS, F.J.A. Plantas medicinais no Brasil; nativas e exóticas. Nova Odessa, SP: Instituto Plantarum. 2002.

MENSAH, J.K.; OKOLI, R.I.; OHAJU-OBODO, J.O.; EIFEDIYI, K. Phytochemical, nutritional and medical properties of some leafy vegetables consumed by Edo people of Nigeria. African Journal of Biotechnology, v.7, p.2304-2309, 2008.

MEYER, B. N.; FERRIGNI, N. R.; PUTNAM, J. E.; JACOBSEN, L. B.; NICHOLS, D. E.; MCLAUGHLIN, J. L. Brine shrimp: a convenient general bioassay for active plant constituents. Planta Medica, v. 45, p. 31-34, 1982.

METCALFE, C.R.; CHALK, L. Anatomy of the dicotyledons: leaves, stem and wood in relation to 
taxonomy with notes on economic uses. Oxford: Clarendon. 1957.

MORS, W.B.; RIZZINI, C.T.; PEREIRA, N.A Medicinal plants of Brazil. Algonac, Michigan: Reference Publications. 2000.

MOTT, K.A.; GIBSON, A.C.; O'LEARY, J.W. The adaptative significance of anphiistomatic leaves. Plant Cell and Environment, v. 5, p. 455-460, 1982.

NAKATA, P.A. Advances in our understanding of calcium oxalate crystal formation and function in plants. Plant Science, v. 146, p. 901-909, 2003.

NESAMVUNI, C.; STEYN, N.P.; POTGIETER, M.J. Nutritional value of wild, leafy plants consumed by the Vhavenda. South African Journal of Science, v. 97, p. 51-54, 2001.

NYA, E.J.; OKORIE, N.U.; EKA, M.J. An economic analysis of Talinum triangulare (Jacq) production/farming in Southern Nigeria. Trends in Agricultural Economics, v.3, p.79- 93, 2010.

O'BRIEN, T.P.; FEDER, N.; MCCULLY, M.E. Polychromatic staining of plant cell walls by toluidine blue. Protoplasma, v. 59, p. 368-373, 1964.

ODHAV, B. et al. 2007. Preliminary assessment of nutritional value of traditional leafy vegetables in KwaZulu-Natal. Journal of Food Composition Analysis, v. 20, p.430-435, 2007.

QUEIROZ, S.S.; TORRES, M.A.A. Anemia ferropriva na infância. Jornal de Pediatria, v. 76, p.298-304, 2000.

QUEIROZ, S.S.; TORRES, M.A.A. Anemia carencial ferropriva: aspectos fisiopatológicos e experiência com a utilização do leite fortificado com ferro. Pediatria Moderna, v. 31, p. 441-455, 1995.
REDDY, N. R.; SATHE, S. K.; SALUNKHE, D. K. Phytates in legumes and cereals. Advance Food Nutrition Research, v. 28, p.1-92, 1982.

SANTOS, J.S. Desenvolvimento e otimização de metodologias para a determinação de nitrogênio. 2007. 102 f. Dissertação (Mestrado em Agroquímica) - Universidade Federal de Viçosa, Viçosa, 2007.

SARRUGE, J.R.; HAAG, H.P. Análises químicas em plantas. Piracicaba: ESALQ, Departamento de Química. 1974.

SEENA, S.; SRIDHAR, K. R.; ARUNB, A.B.; YOUNG, C. C. Effect of roasting and pressure-cooking on nutritional and protein quality of seeds of mangrove legume Canavalia cathartica from southwest coast of India. Journal of Food Composition and Analysis, v.19, p. 284-93, 2006.

SOUZA, V.C.; LORENZI, H. Botânica sistemática. Nova Odessa, SP: Instituto Plantarum. 2005.

TCHIEGANG, C.; AISSATOU, K. Données ethnonutritionnelles et caractéristiques physicochimiques des légumes-feuilles consommés dans la savane de Adamaoua (Cameroun). Tropicultura, v. 22, p. 11-18, 2004.

TOLEDO, A.C.O.; DUARTE, M.R.; NAKASHIMA, T. Caracterização morfoanatômica de raiz e rizoma de Symphytum officinale L. (Boraginaceae). Revista Brasileira de Farmacognosia, v. 16, p. 185-191, 2006.

WAGNER, H.; BLADT, S.; ZGAINSKI, E.M. Plant drug analysis: a thin layer chromatography atlas. Berlim: Springer Verlag. 1984. 